\title{
PENILAIAN CALON NASABAH DALAM MENGAJUKAN KREDIT DENGAN SISTEM PERANKINGAN
}

\author{
Sujarwo \\ Dosen Fakultas Matematika dan Ilmu Pengetahuan Alam \\ Universitas Pesantren Tinggi Darul 'Ulum Jombang \\ *email : jarwo301@gmail.com
}

\begin{abstract}
ABSTRAK
Penelitian ini membangun sebuah sistem perankingan untuk memilih calon nasabah yang layak mendapatkan kredit, karena banyaknya kriteria yang bervariasi maka perlu metode untuk mempermudah penilaian dengan perankingan. PROMETHEE "Preference Ranking Organization Method for Enrichment Evaluation" digunakan dalam Sistem Pendukung keputusan karena kesederhanaan, kejelasan, dan kestabilan dengan melakukan penilaian dari beberapa alternatif kriteria penilaian pengambilan keputusan untuk penentuan urutan (prioritas) dalam analisis multikriteria, seperti halnya pada pemberian kredit dalam suatu bank maupun perusahaan jasa keuangan. Penelitian ini membandingkan perhitungan manual yang selama ini dilakukan oleh pihak bank dengan perhitungan metode PROMETHEE. Dengan metode PROMETHEE kreditur B menempati ranking 3 yang dalam perhitungan manual menempati ranking 2 dan selama angsuran bermasalah, maka dari itu dengan menggunakan metode ini untuk menentukan penilaian kreditur menghasilkan ranking yang lebih baik. Penilaian calon nasabah yang mengajukan kredit dengan sistem perankingan dengan metode PROMETHEE dapat mengetahui ranking dari calon nasabah yang layak mendapatkan kredit. Sehingga masalah kredit macet dapat dihindari.
\end{abstract}

Kata kunci : Promethee; Perankingan; Penilaian; Kreditur 


\begin{abstract}
This research builds a perankingan system for selecting potential borrowers who deserve the credit, because of the many varied criteria it is necessary to simplify the assessment method with perankingan. PROMETHEE "Preference Ranking Method for Organization's Evaluation" is used in decision support Systems because of its simplicity, clarity, and stability by conducting an assessment of some of the alternative criteria for the assessment of decision making for the determination of the order (priority) in the analysis of multikriteria, as well as on granting credit in a bank or financial services company. This study compares the manual for calculation was performed by the bank with the calculation methods of PROMETHEE. PROMETHEE methods with lender B occupies a rank 3 in manual calculation of rank 2 and occupies over troubled installment, therefore using this method to determine the valuation of creditors to determine the valuation of the lender generate a better ranking. Assessment of potential borrowers who apply for credit with perankingan system with the method of PROMETHEE can figure out the ranking of potential borrowers who deserve credit. So the problem of bad credit can be avoided.
\end{abstract}

Keywords: Promethee; Perankingan; Judgment; The Creditor 


\section{Pendahuluan}

Kebutuhan masyarakat dengan perbankan saat ini semakin tinggi, sehingga pihak perbankkan pun banyak permasalahan dalam mengambil sebuah keputusan. Maka dari itu mereka membutuhkan sebuah sistem pendukung keputusan dengan metode yang dapat menyelesaikan suatu masalah terutama penilaian terhadap masyarakat yang mengajukan kredit. Penilaian terhadap calon kreditur memiliki banyak kriteria dan bervariasi, maka dari itu perlu suatu metode untuk mempermudah penilaian dengan perankingan. Karena berdasarkan pada banyaknya kriteria yang bervariasi, penelitian ini menggunakan salah satu metode penentuannya dengan "Multi Criteria Desicion Making” (MCDM) metode PROMETHEE. PROMETHEE "Preference Ranking Organization Method for Enrichment Evaluation" digunakan dalam Sistem Pendukung keputusan karena kesederhanaan, kejelasan, dan kestabilan dengan melakukan penilaian dari beberapa alternatif kriteria penilaian pengambilan keputusan untuk penentuan urutan (prioritas) dalam analisis multikriteria, seperti halnya pada pemberian kredit dalam suatu bank maupun perusahaan jasa keuangan. Metodologi Promethee benarbenar mampu untuk menyelesaikan masalah seleksi pilihan karena prosedur yang sederhana dan fleksibel (Halouni, 2007).

Penelitian mengambil studi kasus di Bank Perkreditan Rakyat (BPR) Sinar Dana yang berkantor pusat di jl. kumitir No. 301 Pilangkenceng Kabupaten
Madiun. Sebagai lembaga keuangan Bank itu tidak hanya menerima simpanan dalam

bentuk deposito berjangka, tabungan, namun BPR Sinar Dana juga memberikan kredit usaha untuk masyarakat untuk meningkatkan usahanya, baik usaha yang berskala kecil, menengah atau besar. Maka dari itu Bank Perkreditan Rakyat Sinar Dana perlu meminimalisasi masalah masalah dan resiko yang terjadi seperti kredit macet.

Metode PROMETHEE mampu mengintegrasikan dalam prosedur baik data kuantitatif maupun kualitatif dalam konteks pasti. Oleh karena itu, penerapan metode ini untuk masalah nyata akan mengarah pada hasil yang lebih baik. Adanya aplikasi ini diharapkan dapat membantu pengambil keputusan dalam menentukan calon nasabah yang tepat untuk diberi kucuran dana kredit serta menyediakan informasi pemberian kredit yang tepat.

Tujuan penelitian ini adalah Menghasilkan sistem penilaian yang mampu menentukan ranking terhadap calon kreditur dengan metode PROMETHEE. Yang harapannya menghasilkan sistem untuk menghindari resiko pemberian kredit.

PROMETHEE adalah metode pengambilan keputusan multikriteria dikembangkan oleh Brans dkk (1996). Ia membandingkan setiap pasangan alternatif untuk setiap kriteria dan nilai alternatif dalam 0 - 1 interval. Nilai f merupakan nilai nyata dari suatu kriteria dan tujuannya berupa prosedur optimasi untuk setiap alternatif yang akan diseleksi a adalah $f(a)$ merupakan evaluasi dari alternatif yang akan diseleksi tersebut untuk setiap 
kriteria. Penyampaian Intensitas dari preferensi ( pilihan) alternatif a terhadap alternatif $b$ sedemikian rupa sehingga:

- $\mathrm{P}(\mathrm{a}, \mathrm{b})=0$, berarti tidak ada beda antara a dan $b$, atau tidak ada preferensi dari a lebih baik dari $b$.

- $\mathrm{P}(\mathrm{a}, \mathrm{b}) \approx 0$, berarti lemah preferensi dari a lebih baik dari $b$.

- $\mathrm{P}(\mathrm{a}, \mathrm{b})=1$, kuat preferensi dari a lebih baik dari $b$.

$\mathrm{P}(\mathrm{a}, \mathrm{b}) \approx 1$, berarti mutlak preferensi dari a lebih baik dari $b$.

Metode PROMETHEE telah banyak digunakan oleh para peneliti untuk menyeleksi atau memilih beberapa alternatif dan kriteria karena metode ini dapat diterapkan untuk semua jenis pengambilan keputusan dengan informasi yang heterogen serta lebih mudah membuat pemodelan untuk pengambilan keputusan ini sesuai dengan preferensi pengambilan keputusan pembuat. Selama proses pengambilan keputusan dan interaksinya dengan analisa, bahwa struktur masalah akan menjadi jelas. Model ini bersama-sama dibangun harus menjadi alat untuk mencari, mengeksplorasi, menafsirkan, perbedaan pendapat dari permasalahan (Roy, 2009; Tsoukiàs, 2008). Beberapa set parameter dapat diterima atau diselidiki dalam rangka untuk mengevaluasi dampak masingmasing pada keputusan yang dihasilkan. Penelitian ini menawarkan kepada para pembuat keputusan aplikasi sederhana dan lebih luas dari metode multikriteria Promethee tanpa mengorbankan salah satu yang menguntungkan dan dengan memperhatikan ketidakakuratan data. Sebuah simulasi numerik dari metode yang diusulkan dilakukan untuk menunjukkan kemungkinan-kemungkinannya

(Halouani, 2007).

Metode PROMETHEE juga digunakan untuk pengambilan keputusan perdagangan saham. Dalam rangka untuk memilih Saham unggulan (alternatif) untuk investasi, harus mempertimbangkan beberapa alternatif yang kadang-kadang bertentangan kriteria. Oleh karena itu, kita dihadapkan dengan masalah multikriteria pengambilan keputusan yang khusus. Hasil penerapan model ini sebagian besar tergantung pada strategi investasi investor. Investor harus menentukan Fungsi preferensi masing-masing kriteria. Pemilihan industri unggul dan perusahaan unggul mungkin berbeda sesuai dengan strategi diterapkan oleh masing-masing individu.

Semua parameter alternatif dan kreteria yang dinyatakan mempunyai pengaruh nyata menurut pandangan ekonomi ( $\mathrm{Hu}$ dan Chiung, 2011 ) dan data dasar untuk evaluasi dengan methode PROMETHEE disajikan pada tabel 1 sebagai berikut :

Tabel 1 tabel metode PROMETHEE

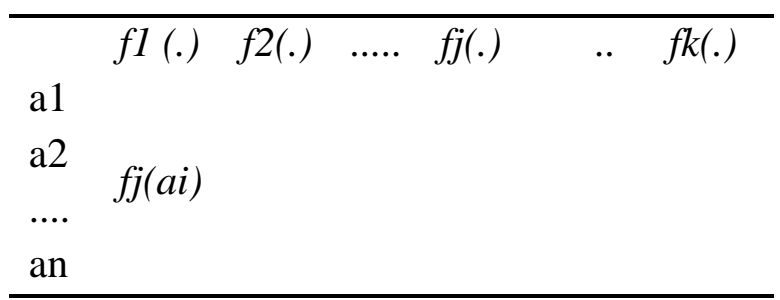

Dimana a1, a2, .... an adalah alternatif alternatif yang di syaratkan dan $f 1, f 2$, ......fk adalah kreteria dari masing - masing alternatif.

Setiap kriteria boleh memiliki nilai dominasi kriteria atau bobot kriteria yang sama atau berbeda, dan nilai bobot tersebut harus di atas 0 (Ying-Hsiu dkk, 2011). Sebelum menghitung bobot untuk 
masing-masing kriteria, maka dihitung total bobot dari seluruh kriteria terlebih dahulu. Berikut rumus untuk perhitungan bobot kriteria :

$$
\begin{gathered}
W_{j}=\frac{W_{i}}{\Sigma W_{i}} \\
\sum W_{j}=1
\end{gathered}
$$

ket $: \mathrm{W}_{\mathrm{j}}=$ Pembobotan

$\mathrm{W}_{\mathrm{n}}=$ jumlah bobot tiap kriteria

$\sum \mathrm{W}_{\mathrm{n}}=$ jumlah total semua kriteria

Rumus perbandingan untuk setiap alternatif, sebagai berikut :

$$
\pi\left(a_{1}, a_{i}\right)=\sum_{j=1}^{j} W_{j} \times P_{j}\left(a_{1}, a_{i}\right)
$$

Ket : $\pi=$ nilai perbandingan tiap alternatif

$\mathrm{a}_{1}=$ alternatif 1

$\mathrm{a}_{\mathrm{i}}=$ alternatif ke-n

$P_{j}=$ perbandingan dengan kriteria

Perangkingan yang digunakan dalam metode PROMETHEE meliputi tiga bentuk antara lain :

a. Entering flow

Entering flow adalah jumlah dari yang memiliki arah mendekat dari titik a dan hal ini merupakan karakter pengukuran outrangking. Untuk setiap nilai a dalam grafik nilai outrangking ditentukan berdasarkan entering flow dengan persamaan:

$$
\emptyset^{+}(a)=\frac{1}{n-1} \sum_{x \in a} p(a, x)
$$

Ket : $\emptyset^{+}=$entering flow

$\mathrm{n} \quad=$ jumlah alternatif

$\mathrm{p}(\mathrm{a}, \mathrm{x})=$ preferensi a terhadap $\mathrm{x}$

b. Leaving flow

Sedangkan Leaving flow adalah jumlah dari yang memiliki arah menjauh dari titik a. dan hal ini merupakan pengukuran outrangking. Adapun persamaannya:

$$
\emptyset^{-}=\frac{1}{n-1} \sum p(a, x)
$$

Ket : $\emptyset^{-}=$leaving flow

$$
\mathrm{n}=\text { jumlah alternatif }
$$

c. Net Flow

$$
\mathrm{p}(\mathrm{a}, \mathrm{x})=\text { preferensi a terhadap } \mathrm{x}
$$

Sehingga pertimbangan dalam penentuan Net flow diperoleh dengan persamaan :

$$
\begin{gathered}
\emptyset=\emptyset^{+}(a)-\emptyset^{-}(a) \\
\text { Ket: } \quad \emptyset^{=} \text {net flow } \\
\emptyset^{+}=\text {entering flow } \\
\emptyset^{-}=\text {leaving flow }
\end{gathered}
$$

Semakin besar nilai Entering flow dan semakin kecil Leaving flow maka alternatif tersebut memiliki kemungkinan dipilih yang semakin besar. Perangkingan dalam PROMETHEE I dilakukan secara parsial, yaitu didasarkan pada nilai Entering flow dan Leaving flow. Sedangkan PROMETHEE II termasuk perangkingan komplek karena didasarkan pada nilai Net flow masingmasing alternatif yaitu alternatif dengan nilai Net flow lebih tinggi menempati satu rangking yang lebih baik.

Kredit adalah penyediaan uang atau tagihan yang dapat dipersamakan dengan itu, berdasarkan persetujuan atau kesepakatan pinjam-meminjam antara bank dengan pihak lain yang mewajibkan pihak peminjam untuk melunasi utangnya setelah jangka waktu tertentu dengan pemberian bunga (UU NO.10 TAHUN 1998).

Bank adalah badan usaha yang menghimpun dana dari masyarakat dalam bentuk simpanan dan menyalurkannya kepada masyarakat dalam bentuk kredit 
dan atau bentuk bentuk lainnya dalam rangka meningkatkan taraf hidup rakyat banyak(UU No.10 Tahun 1998).

Penerima kredit adalah siapa saja yang mendapat kredit dari bank dan wajib mengembalikannya setelah jangka waktu tertentu. Istilah siapa saja di sini mempunyai arti luas yang meliputi perseorangan dan badan usaha. Bank-bank dalam menilai suatu permintaan berpedoman kepada faktor-faktor antara lain:

a) Watak (character)

b) Kemampuan (capacity)

c) Modal (capital)

d) Jaminan (collateral) dan

e) Kondisi ekonomi (condition of economy).

Kelima syarat-syarat itu merupakan ukuran kemampuan penerima kredit untuk mengembalikan pinjamannya.

Ke-lima faktor diatas dijadikan pedoman semua bank dengan mengembangkan menjadi beberapa kreteria, termasuk BPR Sinar Dana seperti terlihat pada tabel 2 dibawah ini.

Tabel 2 Daftar Kreteria

\begin{tabular}{ll} 
Kd & kriteria \\
f1 & Berkas Persyaratan \\
f2 & Pekerjaan \\
f3 & penghasilan / bulan \\
f4 & pengeluaran / bulan \\
f5 & Dokumen pendukung \\
f6 & Referensi \\
f7 & Historis nasabah \\
f8 & angsuran lain-lain \\
f9 & Jaminan kredit \\
f10 & Tujuan kredit \\
f11 & Besar kredit \\
f12 & Suku bunga \\
\hline
\end{tabular}

f13 Masa kredit

f14 Harga jaminan

f15 Rekening listrik

f16 Rekening PBB

f17 SPPT

Untuk itu diperlukan sebuah manajemen kredit yang bisa membantu menganalisa kelayakan pemberian kredit kepada nasabah mengingat pentingnya analisa kredit.

\section{Metodologi Penelitian}

Bahan yang dibutuhkan dalam penelitian ini adalah data kreteria kriteria apa saja yang dibutuhkan pihak Bank untuk memberi kredit kepada nasabah. Setiap bank memiliki kreteria yang berbeda beda, hal ini tergantung dari kebijakan pengambil keputusan di Bank tersebut. Maka dari itu penelitian ini mengambil studi di BPR Sinar Dana Madiun agar lebih terfokus. Penelitian ini dapat dikembangkan sesuai kebutuhan pihak pengguna. Bahan yang dibutuhkan dalam penelitian ini adalah data kreteria kriteria apa saja yang dibutuhkan pihak Bank untuk memberi kredit kepada nasabah. Setiap bank memiliki kreteria yang berbeda beda, hal ini tergantung dari kebijakan pengambil keputusan di Bank tersebut. Maka dari itu penelitian ini mengambil studi di BPR Sinar Dana Madiun agar lebih terfokus. Penelitian ini dapat dikembangkan sesuai kebutuhan pihak pengguna. Kreteria kreteria yang diterapkan di BPR Sinar Dana untuk penentuan pemberian kredit terlihat pada tabel 2.

Pada metode Promthee untuk menghitung rangking calon nasabah yang layak mendaptakan kredit di perlukan data beberapa alternatif / nasabah yang dinilai berdasarkan pada kriteria yang sudah 
ditentukan, kemudian dihitung selisih dari kriteria alternatif a dan alternatif b, yang nantinya akan di gunakan untuk menghitungkan indeks preferensi dari beberapa alternatif untuk menghitung entering flow, leaving flow dan net flow. Perangkingan ini adalah untuk yang parsial hanya didasarkan pada salah satu perhitungan antara entering flow dan net flow, sedang kan untuk perangkingan komplet di dasarkan pada ketiga perhitungan yaitu entering flow, leaving flow dan net flow yaitu selisih antara entering flow dan net flow.

Langkah-langkah perhitungan dengan metode PROMETHEE adalah menghitung outrangking dengan menggunakan metode PROMETHEE yang pertama dilakukan adalah Menentukan beberapa alternatif, menentukan beberapa criteria setelah itu dilanjutkan dengan menentukan dominasi kriteria / nilai kecenderungan ( Treshold) atau biasa disebut dengan nilai parameter $\mathrm{p}$ dan $\mathrm{q}$ dimana jika $\mathrm{x} \leq \mathrm{q}$ maka antara criteria satu dengan criteria dua adalah Indeferensi (tidak ada beda $/ \mathrm{x}=0$ ) dan jika $\mathrm{x} \geq \mathrm{p}$ maka nilai $\mathrm{x}=1$ Preference (Mutlak) setelah itu dilanjutkan dengan menentukan tipe penilaian, dimana tipe penilaian memiliki 2 tipe yaitu: minimum dan maksimum. Menentukan tipe preferensi untuk setiap kriteria yang paling cocok didasarkan pada data dan pertimbangan dari decision maker. Tipe preferensi ini berjumlah Enam ( Usual, Quasi, Linier, Level, Level Criterion, Linier Quasi dan Gaussian) berikutnya dilakukan Perhitungan Entering flow, Leaving flow dan Net flow untuk menentukan outrangking, dalam PROMETHEE ada dua perangkinganya itu perangkingan parsial yang hanya berdasarkan pada perhitungan entering flow atau leaving flow dan perangkingan complete berdasarkan pada perhitungan net flow atau selisih dari nilai entering flow dengan leaving flow. ( Behzadian dkk, 2010 ).

\section{Hasil penelitian dan Pembahasan}

Hasil Penelitian

Penelitian mengambil sampel data calon nasabah tahun 2013, karena menyangkut etika dan kerahasiaan pihak bank calon kreditur diberi nama dengan inisial huruf A dan seterusnya. Perhitungan yang selama ini dilakukan oleh BPR yaitu menilai calon nasabah dari kreteria kreteria tersebut diatas dengan "Baik" nilai $=3$, "Cukup Baik" nilai $=2$ dan "Kurang Baik" nilai $=1$ setelah itu dijumlahkan nilainya. Yang memiliki nilai total nilai tertinggi mendapatkan ranking 1, ranking 2 dan seterusnya. Berdasarkan hasil perhitungan menghasilkan ranking $1=\mathrm{A}$, ranking $2=\mathrm{B}$, dan ranking $3=\mathrm{C}$. Namun dalam perjalanan waktu dalam pembayaran angsuran Kreditur B terjadi kredit macet, setelah di analisis ternyata nasabah B lemah pada kreteria pekerjaan, maka dari itu pada penilaian kreteria ke-2 atau pekerjaan harus mendapatkan perhatian secara serius.

Hasil penelitian yang telah dilakukan dengan menerapkan metode PROMETHEE untuk menentukan prioritas pemberian kredit menampilkan laporan perankingan data nasabah mulai ranking pertama sampai terakhir. Dengan laporan itu pihak pengambil keputusan bisa mengambil kebijakan sampai ranking ke berapa yang akan mendapatkan kredit dengan memperhatikan keseimbangan neraca keuangan bank. Dari tabel 2 dibuat 
pembobotan pada masing masing kriteria menghasilkan :

Tabel 3 Tabel Pembobotan

\begin{tabular}{|c|c|c|c|}
\hline Nama & Nilai & bobot & Scoring \\
\hline Baik & 99.96 & 5.88 & 9 \\
\hline Cukup & 49.98 & 2.94 & 4 \\
\hline Kurang & 2.98 & 1.96 & 2 \\
\hline & \multicolumn{2}{|l|}{ Total } & 15 \\
\hline
\end{tabular}

Nilai baik disini di dapatakan dari mengalikan nilai setiap point, dimana setiap point kriteria memiliki nilai bobot 5.88, nilai bobot tersebut di peroleh dari $\frac{100}{f n}$, (fn) adalah jumlah dari keseluruhan kriteria. Seperti pada perhitungan di bawah ini.

$\frac{100}{17}=5.88$ dan total keseluruhan dari point tersebut adalah $5.88 \times 17=$ 99.96 (Baik) jika semua point bernilai baik, dan jika point tersebut bernilai cukup maka nilai bobotnya adalah sebagai berikut :

$\frac{1}{2} \times 5.88=2.94 \quad$ sedangkan jumlah nilainya untuk kriteria bernilai cukup adalah $99.96 \times \frac{1}{2}=49.98$ ( cukup)

sedangkan jika bobotnya bernilai kurang maka nilainya adalah $\frac{1}{3} \times 5.88=1.96$. dan jumlah nilai untuk kriteria yang bernilai kurang adalah $99.96 \times \frac{1}{3}=$ 2.98 (kurang)

Setelah dilakukan penilaian pada setiap kriteria dari alternatif, selanjutnya adalah dengan menentukan nilai kecenderungan dari parameter yang digunakan pada setiap kriteria. Nilai ini ditentukan secara simultan.
Jika nilai kecenderungannya sudah ditentukan maka langkah selanjutnya adalah menghitung nilai $|\mathrm{d}|$ atau nilai preferensi yang di dapatkan dari selisih bobot kriteria antar alternatif $|\mathrm{d}|=$ $\mathrm{f}(\mathrm{a} 1)-\mathrm{f}(\mathrm{a} 2)$

Nilai perhitungan preferensi $\left(a_{1}, a_{2}\right)$

(f1) $|\mathrm{d}|=5.88-5.88=0$

$\mathrm{P}(\mathrm{a} 1, \mathrm{a} 2)=0$

$\mathrm{P}(\mathrm{a} 2, \mathrm{a} 1)=0$

berdasarkan kaidah minimasi tipe referensi

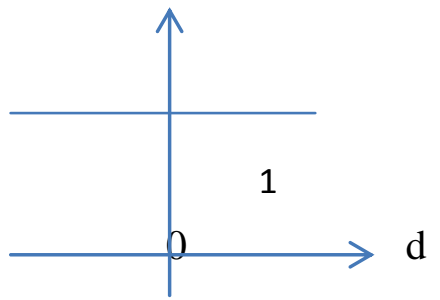

1 yaitu :

(f2) $|\mathrm{d}|=2.94-5.88=-2,94$

Berdasarkan kaidah maximasi tipe referensi 1

$\mathrm{P}(\mathrm{a} 1, \mathrm{a} 2)=0 \quad \mathrm{p}(\mathrm{a} 2, \mathrm{a} 1)=1$

(f3) $|\mathrm{d}|=1,96-5,88=-3.92$

Berdasarkan kaidah maximasi preferensi tipe IV maka

$\mathrm{P}(\mathrm{a} 1, \mathrm{a} 2)=0 \mathrm{p}(\mathrm{a} 2, \mathrm{a} 1)=0.5$

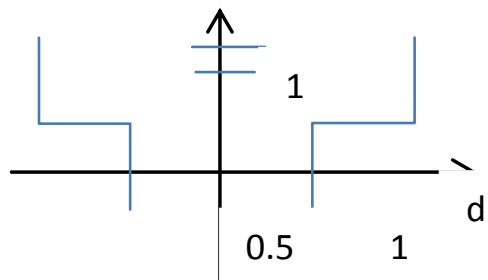

(f10) $|\mathrm{d}|=5.88-1.96=3.92$ berdasrkan kaidah maxsim 1

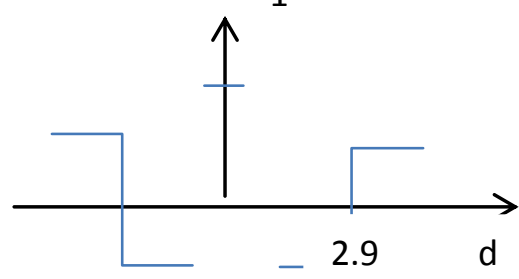

$\operatorname{Maka} \mathrm{p}(\mathrm{a} 1, \mathrm{a} 2)=1 \mathrm{p}(\mathrm{a} 2, \mathrm{a} 1)=0 . \mathrm{dst}$ 
Yang nantinya hasilnya seperti pada tabel 4.

Tabel 4 Tabel Perhitungan Preferensi

\begin{tabular}{|l|l|l|l|l|l|}
\hline $\begin{array}{l}\mathrm{p}(\mathrm{a} 1, \mathrm{a} 2 \\
\text { 2 }\end{array}$ & $\begin{array}{l}\mathrm{p}(\mathrm{a} 2, \mathrm{a} 1 \\
\text { (a) }\end{array}$ & $\begin{array}{l}\mathrm{p}(\mathrm{a} 2, \mathrm{a} 3 \\
\mathrm{p}(\mathrm{a} 3, \mathrm{a} 2\end{array}$ & $\begin{array}{l}\mathrm{p}(\mathrm{a} 1, \mathrm{a} 3 \\
\mathrm{p}(\mathrm{a} 3, \mathrm{a} 1\end{array}$ \\
\hline 0 & 0 & 0 & 0 & 0 & 0 \\
\hline 0 & 1 & 1 & 0 & 0 & 0 \\
\hline 0 & 0.5 & 0.5 & 0 & 0 & 0 \\
\hline 0 & 0 & 0 & 0 & 0 & 0 \\
\hline 0 & 0 & 0 & 0 & 0 & 0 \\
\hline 0 & 0 & 0 & 0 & 0 & 0 \\
\hline 0 & 0 & 0 & 0 & 0 & 0 \\
\hline 0.5 & 0 & 0 & 1 & 1 & 1 \\
\hline 0 & 0 & 0 & 0 & 0 & 0 \\
\hline 1 & 0 & 0 & 1 & 0 & 0 \\
\hline 0 & 0 & 0 & 0 & 0 & 0 \\
\hline 0 & 0 & 0 & 0 & 0 & 0 \\
\hline 0 & 0 & 0 & 0 & 0 & 0 \\
\hline 1 & 0 & 0 & 0 & 0 & 0 \\
\hline 0 & 0 & 0 & 0 & 0 & 0 \\
\hline 0 & 0 & 0 & 0 & 0 & 0 \\
\hline 0 & 0 & 1 & 0 & 1 & 0 \\
\hline
\end{tabular}

Dari tabel di atas langkah selanjutnya adalah menghitung indeks prefernsi dengen menggunakan rumus $\varphi=$ $\sum_{n=1}^{n} p(a, b) \frac{1}{f n}$ $\varphi p(a 1, a 2)=(0+0+0+0+0+0+1+$ $0+1+0+0+1+0+0+1) 1 / 17=$ 0,15625

$\varphi p(a 2, a 1)=(0+1+1+0+0+0+0+$ $0+0+0+0+0+0.5+0+0) 1 / 17=$ 0.09375

$\varphi p(a 2, a 3)=(0+0+0+0+0+0+0+$ $1+0+1+0+0+1+0+0) 1 / 17=$ 0.15625

$\varphi p(a 3, a 2)=(0+0+0+0+0+0+0+$ $1+0+1+0+0+1+0+0) 1 / 17=0.125$ $\varphi p(a 1, a 3)=(0+0+0+0+0+0+0+$ $0+1+0+0+0+0+0+1) 1 / 17=$ 0.0625 $\varphi p(a 3, a 1)=(0+0+0.5+0+0+0+0$ $+0+0+0+0+0+0+0+0) 1 / 17=$ 0.0625

Tabel 5 Hasil Indeks Preferensi

\begin{tabular}{|l|l|r|r|}
\hline & A & \multicolumn{1}{l|}{ B } & \multicolumn{1}{l|}{ C } \\
\hline A & \multicolumn{1}{|l|}{-} & 0.09375 & 0.0625 \\
\hline B & 0.15625 & - & 0.125 \\
\hline C & 0.0625 & 0.09375 & - \\
\hline
\end{tabular}

Selanjutnya adalah perhitungan Alternative A $\Phi+($ leaving flow $)=\frac{1}{3-1}(0.09375+$ $0.0625=0.078125$

$\Phi-($ Entering flow $)=\frac{1}{3-1}(0.15625+$ $0.0625=0.109375$

$\Phi($ Net flow $)=(0,078125-0,109375)=-$ 0.03125

Alternative B

$\Phi+($ leaving flow $)=\frac{1}{3-1}(0.15625+$ $0.125=0.14075$

$\Phi-($ Entering flow $)=\frac{1}{3-1}(0.09375+$ $0.09375=0.515625$

$\Phi($ Net flow $)=(0.14075-0.515625)=-$ 0.374875

Alternative C

$\Phi+($ leaving flow $)=\frac{1}{3-1}(0.0625+$ $0.09375=0.078125$

$\Phi-($ Entering flow $)=\frac{1}{3-1}(0.0625+$ $0.125=0.09375$

$\Phi($ Net flow $)=(0.078125-0,09375)=-$ 0.015625

Dari perhitungan leaving flow, entering flow dan net flow hasilnya digunakan untuk out rangking baik secara parsial maupun complete namun pada aplikasi yang akan dibangun hanya menggunakan 
perangkingan secara complete. Dari hasil perangkingan tersebut nasabah yang paling utama mendapatkan yang memiliki peringkat paling atas.

Tabel 6 Tabel Perangkingan

\begin{tabular}{|l|c|c|c|l|}
\hline Alternatif & $\emptyset^{+}$ & $\emptyset^{-}$ & $\emptyset$ & RK \\
\hline A & 0.078 & 0.109 & 0.312 & 1 \\
\hline B & 0.140 & 0.187 & -0.374 & 3 \\
\hline C & 0.078 & 0.093 & -0.015 & 2 \\
\hline
\end{tabular}

Berdasarkan perhitungan analisis data dengan menggunakan metode PROMETHEE diatas, calon nasabah A mempunyai nilai leaving flow $=0.078125$, entering flow $=0.109375$, net flow $=$ 0.3125. net flow A atau alternatif pertama memiliki nilai yang paling besar sehingga menempati ranking pertama.

\section{Pembahasan}

Penelitian ini membandingkan perhitungan manual yang selama ini dilakukan oleh pihak bank dengan perhitungan metode PROMETHEE yang ditunjukan pada tabel 4.1.

Tabel 7 Perbandingan perankingan perhitungan manual dengan metode PROMETHEE

\begin{tabular}{llll}
\hline \multicolumn{2}{l}{$\begin{array}{l}\text { MANUAL } \\
\text { Nama }\end{array}$} & ranking & $\begin{array}{l}\text { PROMETHEE } \\
\text { ranking }\end{array}$ \\
& nilai & & \\
\hline A & 48 & 1 & 1 \\
B & 48 & 2 & 3 \\
C & 46 & 3 & 2
\end{tabular}

Dengan metode PROMETHEE kreditur B menempati ranking 3, maka dari itu dengan menggunakan metode ini untuk menentukan penilaian kreditur menghasilkan ranking yang lebih baik.

\section{Kesimpulan}

Penilaian calon nasabah yang mengajukan kredit dengan sistem perankingan dengan metode PROMETHEE dapat mengetahui ranking dari calon nasabah yang layak mendapatkan kredit. Sehingga masalah kredit macet dapat dihindari.

\section{Daftar Pustaka}

Albadvi, S. Kamal Chaharsooghi, Akbar Esfahanipour, 2005, Decision making in stock trading: An application of PROMETHEE, Tehran, Iran, 673-683

Brans, J. P., Vincke, Ph., \& Mareschal, B. 1996. How to select and how to rank projects: The PROMETHEE method. European Journal of Operational Research, 24, 228-238.

Chou, Tien-Yin, Wen-Tzu Lin, ChaoYuan Lin, Wen-Chieh Chou and Pi-Hui Huang, 2004, Application of The Promethee Technique to determine depression outlet location and flow direction in DEM, Departments of land management, Feng-Chia University, Taiwan

Majid Behzadian, R.B. Kazemzadeh, A. Albadvi, M. Aghdasi. 2010. PROMETHEE: A comprehensive literature review on methodologies and applications. Department of Industrial Engineering, Faculty of Engineering, Shomal University, Amol, Iran 
Halouani $^{\mathrm{a}}$,*, H. Chabchoub ${ }^{\mathrm{a}}$, J.-M. Martel ${ }^{\mathrm{b}}$ 2007, PROMETHEE-MD-2T method for project selection, a University of Economic Sciences and Management, Sfax, Tunisia, b Laval University, Quebec, Canada, 841849.

Rudolf Vetschera, Adiel Teixeirade Almeida, 2012, A PROMETHEEbased approach to portfolio selection problems, University of Vienna, A 1210 Vienna, Austria b Federal University of Pernambuco,Recife PE50. 630-970,Brazil, 1010 -1020.

Yi-Chung Hu, Chiung-Jung Chen, 2011,A PROMETHEE - based classification method using concordance and discordance relations and its application to bankruptcy prediction Department of Business Administration, Chung Yuan Christian University, Chung-Li 32023, Taiwan,

Yilmaz Burcu, Metin Dag deviren, 2011, A combined approach for equipment selection: F-PROMETHEE method and zero-one goal programming, Department of Industrial Engineering, Faculty of Engineering, Gazi University, 06570 Maltepe, Ankara, Turkey 